\title{
Comparative profiling of the transcriptional response to iron restriction in six serotypes of Actinobacillus pleuropneumoniae with different virulence potential
}

\author{
Kirstine Klitgaard ${ }^{1 *}$, Carsten Friis ${ }^{2}$, Øystein Angen ${ }^{1}$, Mette Boye ${ }^{1}$
}

\begin{abstract}
Background: Comparative analysis of gene expression among serotypes within a species can provide valuable information on important differences between related genomes. For the pig lung pathogen Actinobacillus pleuropneumoniae, 15 serotypes with a considerable variation in virulence potential and immunogenicity have been identified. This serotypic diversity can only partly be explained by amount of capsule and differences in the RTX toxin genes in their genomes. Iron acquisition in vivo is an important bacterial function and in pathogenic bacteria, iron-limitation is often a signal for the induction of virulence genes. We used a pan-genomic microarray to study the transcriptional response to iron restriction in vitro in six serotypes of $A$. pleuropneumoniae $(1,2,3,5 b, 6$, and 7$)$, representing at least two levels of virulence.

Results: In total, 45 genes were significantly $(p<0.0001)$ up-regulated and 67 genes significantly down-regulated in response to iron limitation. Not previously observed in A. pleuropneumoniae was the up-regulation of a putative cirAlike siderophore in all six serotypes. Three genes, recently described in A. pleuropneumoniae as possibly coding for haemoglobin-haptoglobin binding proteins, displayed significant serotype related up-regulation to iron limitation. For all three genes, the expression appeared at its lowest in serotype 3, which is generally considered one of the least virulent serotypes of $A$. pleuropneumoniae. The three genes share homology with the $h m b R$ haemoglobin receptor of Neisseria meningitidis, a possible virulence factor which contributes to bacterial survival in rats.

Conclusions: By comparative analysis of gene expression among 6 different serotypes of A. pleuropneumoniae we identified a common set of presumably essential core genes, involved in iron regulation. The results support and expand previous observations concerning the identification of new potential iron acquisition systems in $A$. pleuropneumoniae, showing that this bacterium has evolved several strategies for scavenging the limited iron resources of the host. The combined effect of iron-depletion and serotype proved to be modest, indicating that serotypes of both moderate and high virulence at least in vitro are reacting almost identical to iron restriction. One notable exception, however, is the haemoglobin-haptoglobin binding protein cluster which merits further investigation.
\end{abstract}

\section{Background}

Actinobacillus pleuropneumoniae, is a Gram-negative, facultative anaerobic coccobacillus of the Pasteurellaceae family [1]. It is the causative agent of porcine pleuropneumonia. This highly infectious disease causes

\footnotetext{
* Correspondence: kksc@vet.dtu.dk

'National Veterinary Institute, Technical University of Denmark, Bülowsvej 27, DK-1790, Copenhagen, Denmark

Full list of author information is available at the end of the article
}

impaired animal welfare and serious economic losses in the swine industry, world-wide. The infection can lead to both peracute disease with rapid death and chronic infection resulting in asymptomatic carriers [2]. Based on differences in capsular polysaccharides, 15 serotypes have been recognized [3]. The serotypes differ greatly in both virulence potential, immunogenicity and in geographical distribution [4-8]. Due to differences in immunogenicity, vaccines raised against one serotype

\section{Biomed Central}


do not provide protection from infection by other serotypes [8].

A number of virulence factors have been described for A. pleuropneumoniae [2,9-11]. Serotype variations in virulence potential seem to be primarily governed by the amount of capsule and the combination of RTX toxins, denoted apxI, apxII, and apxIII, produced by the individual serotypes $[12,13]$. The most virulent combination, apxI and apxII, is produced by serotypes 1, 5, 9, and 11 . ApxII and apxIII are found in the medium virulent serotypes $2,3,4,6,8$, and 15 . The remaining serotypes produce one toxin: apxII by serotypes 7,12 , and 13 and apxI by serotypes 10, and 14 [12]. Serotypes 7 and 12 are also considered to be of medium virulence, while serotypes 10, 13 and 14 are only rarely isolated from disease $[4,14]$. Still, observations of variation in pathogenic potential, even among serotypes and strains expressing the same $a p x$ toxins, indicate that other virulence determinants must be contributing to the observed differences in pathogenesis [2,15-17]. Serotype 3 is generally believed to be less virulent than the remaining types [4,18], although some serotype 3 strains showed no difference in pathogenicity when compared to other apxII/apxIII producing serotypes [7,17].

An important virulence factor for bacteria is the ability to survive and grow in an iron-limited environment [2]. Iron is involved in metabolic pathways, respiration, oxygen transport, DNA synthesis and synthesis of metabolites $[19,20]$ and is critical to the invading microorganisms for establishing infection. As part of the innate defense, the mammalian host keeps the levels of intracellular free iron to around $10^{-18} \mathrm{M}$ which is insufficient to allow bacterial growth [19]. The low level of free iron in the host is maintained by high affinity proteins such as transferrin, lactoferrin, haem, haemoglobin $(\mathrm{Hb})$, and ferritin [19].

Like other pathogens, A. pleuropneumoniae has adapted a number of strategies for scavenging host iron. The bacterium is able to use porcine transferrin as well as haem proteins as sole sources of iron. A. pleuropneumoniae genes known to be involved in iron uptake are the porcine transferrin specific outer membrane (OM) proteins, $t b p A$ and $t b p B$, the co-transcribed $t o n B-e x b B$ exbD complex [21-23], and the second ton $B$ system, designated exbB2-exbD2-tonB2 [24]. Solely responsible for the $\mathrm{Hb}$ uptake in $A$. pleuropneumoniae is the haemoglobin binding protein, $h g b A$ [25]. The presence of a periplasmic binding protein-dependent transport system, homologuous to $y f e A B C D$ of Yersinia pestis has been documented in A. pleuropneumoniae and other Pasteurellaceae species [26-29]. A gene cluster sharing homology with the $H m b R \mathrm{Hb}$ receptor from $N$. meningitides has recently been identified by microarray analysis [26] In A. pleuropneumoniae, the putative Actinobacillus ferric uptake operon, $a f u A B C$, and the siderophore ferrichrome uptake, $f h u$, receptor are not regulated by iron-levels [30-33].

In many bacteria the intracellular iron level and utilization is controlled by the balance between the regulatory protein, fur (ferric-uptake regulator protein), and ryhB $[20,34]$. Fur is a global gene regulator involved in numerous functions of the cell, such as respiration, glycolysis, purine metabolism, and redox-stress resistance [20]. It represses transcription upon interaction with its co-repressor $\mathrm{Fe}^{2+}$, and causes de-repression in the absence of $\mathrm{Fe}^{2+}$ [19]. The fur regulated ryhB, a small non-coding RNA (sRNA), acts by repressing iron-using proteins under iron-restricted conditions [20]. Whether ryhB or other sRNAs are involved in the regulatory response of Pasteurellaceae remains to be demonstrated. Recently, however, homologues of the global sRNA regulator, Hfq, a key factor in regulations by sRNAs in bacteria, has also been identified in A. pleuropneumoniae, $P$. multocida, and $H$. influenza [35]. Among the many Hfq-dependent regulators is ryhB [35].

Microarray analysis of gene regulation under iron restriction have been studied in A. pleuropneumoniae, Pasteurella multocida, Haemophilus influenza, Mannheimia haemolytica, and Haemophilus parasuis, respectively [26-29,36]. Presently, however, the knowledge of intra-species variation in response to iron deprivation is limited for the Pasteurellaceae family. Only few comparative transcriptional profiling studies have been performed in this group and none for A. pleuropneumoniae [37]. We used an in vitro model system to compare the response of moderate (serotypes $2,3,6,7$ ), and highly virulent strains (serotypes 1 and 5) of A. pleuropneumoniae to the iron restricted conditions found in the porcine host. The primary aims were: 1) to identify any variations in the transcriptional response among the serotypes which might contribute to the explanation of the observed differences in virulence, 2) to identify a set of genes defining the core modulon of $A$. pleuropneumoniae in response to iron limitation, 3) to develop a valid method for transcriptional comparison of multiple serotypes.

\section{Results \& Discussion}

\section{Microarray analysis of $A$. pleuropneumoniae iron} regulation

Based on all the sequence information available for $A$. pleuropneumoniae, we designed a pan-genomic microarray, targeting the $A$. pleuropneumoniae serotypes $1,2,3$, 5,6 , and 7 , respectively. This array was used to study the gene expression of all the above mentioned serotypes in response to iron limitation. The study set-up was established in a previous investigation [38]. Briefly, gene expression of bacteria grown for $30 \mathrm{~min}$ in the 
presence of $300 \mu \mathrm{M}$ of the iron chelator 2,2'-dipyridyl was compared to control cultures. The length of the iron limitation period was chosen on the basis of previous results, where expression of $t b p A$ and $\operatorname{exbB}$ appeared to reach maximum level $30 \mathrm{~min}$ after the addition of an iron chelator [38]. Still, a longer iron starvation period may have revealed more genes to be significantly altered by iron deprivation. For each serotype, the growth experiment was performed in four replicas on different days. Real-time quantitative RTPCR (qPCR) was used to verify the microarray results on a sub-set of 18 up- or down-regulated genes, representing a wide range of $\log _{2}$ ratio values (Figure 1). Three previously validated reference genes were used for normalization of the qPCR data [38]. Of the two methods, qPCR displayed the greatest dynamic range. Still, a correlation of 0.93 between microarray and qPCR $\log _{2}$ expression ratios (Spearman's Rho, $\mathrm{p}<3.51 \times 10^{-8}$, $\mathrm{df}=16)$ demonstrated that the results of the two platforms correlated very well with each other. Additionally, cDNA from samples of serotype 2 and 6 grown in iron replete media (2,2'-dipyridyl and ammonium iron(II) sulfate hexahydrate) were included in the qPCR analysis. Comparing the bacterial expression in iron replete versus iron deplete media (only 2,2'-dipyridyl added), nearly all the tested genes were oppositely or much less up- or down-regulated in the iron replete media of both serotypes (Additional file 1 Figure S1). Only one gene, $\operatorname{cop} A$, was up-regulated in both iron deplete and replete cells of serotype 6. Based on the results of the qPCR analysis, along with previous observation by other researchers using the same iron chelator $[27,29]$, we concluded that most of the observed differences in the microarrays were actually due to iron deprivation and not the addition of 2,2'-dipyridyl.

Of the 4876 target genes on the microarray, a total of 112 genes were found to be significantly expressed ( $\mathrm{p}<$ 0.0001 ; estimated false positive error rate of $0.5 \%$ ) in all six serotypes under iron depleted conditions. Of these, 45 were up-regulated (Table 1) and 67 were down-regulated (Table 2). When estimating the combined effect of treatment and serotype, 12 genes also displayed significant $(\mathrm{p}<0.0001$; estimated false positive error rate of $0.5 \%$ ) serotype related response to iron limitation, three were up-regulated and 9 down-regulated (marked in Table 1 and 2). A quick overview of the general distribution of the significantly regulated genes is provided in the genomic atlases depicting the gene expression of all the included serotypes (Figure 2). When classifying the significantly regulated genes according to the Clusters of

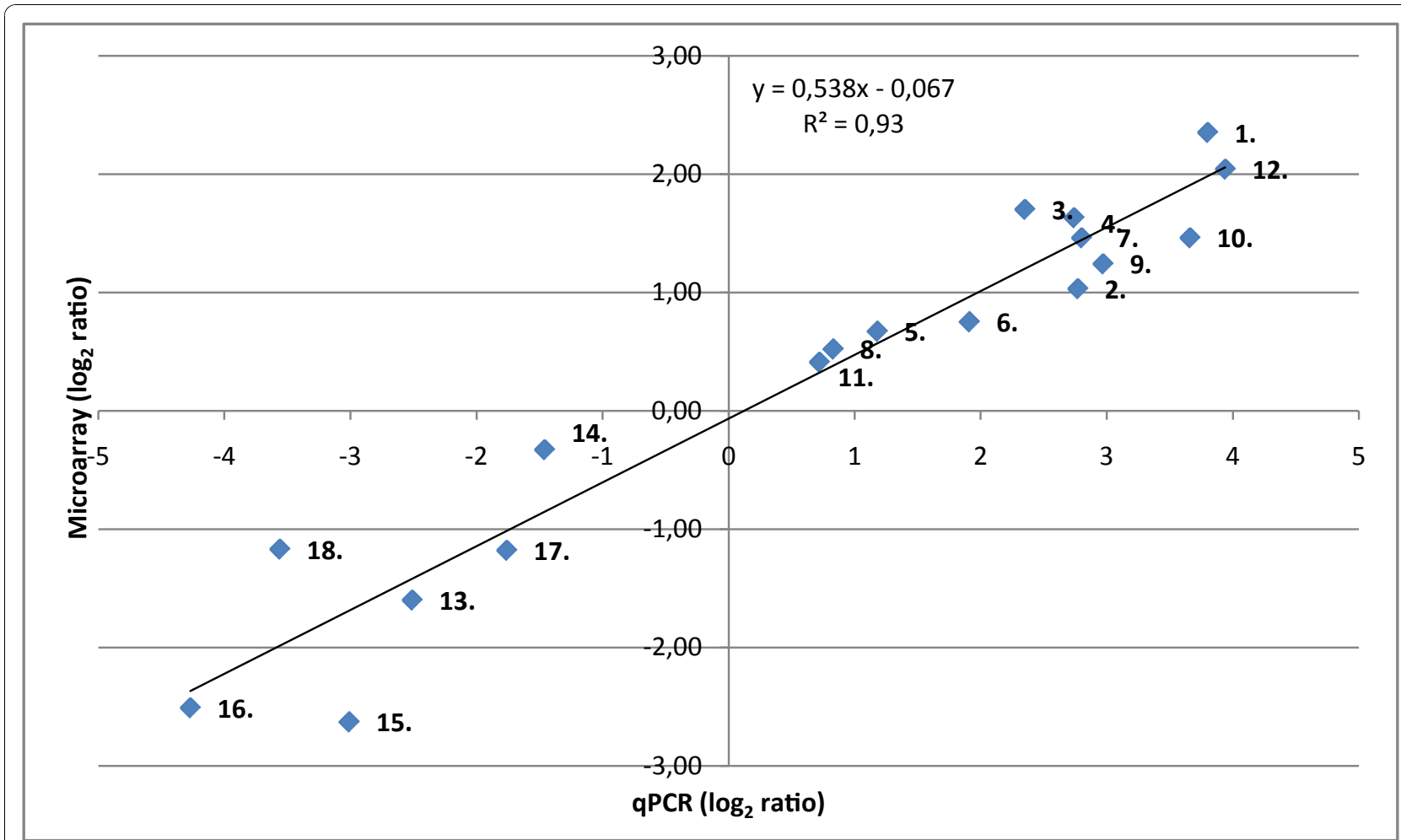

Figure 1 qPCR validation of microarray results. Mean $\log _{2}$ ratios of qPCR results, based on all the included serotypes, are plotted against the mean $\log _{2}$ ratios of the microarray analysis. Included are twelve up-regulated and six down-regulated genes representing a range of log 2 ratio values. The numbers on the graph refer to genes listed in Table 4. 
Table 1 Genes up-regulated in A. pleuropneumoniae under iron limitation

\begin{tabular}{|c|c|c|c|c|}
\hline Locus tag* & Gene & Gene function & COGs* & $\begin{array}{l}\text { Ratio } \\
(\log 2)\end{array}$ \\
\hline APL_2002 & - & hypothetical protein & $P$ & 0.75 \\
\hline APL_1974 & $\operatorname{argD1}$ & diaminobutyrate-2-oxoglutarate aminotransferase & $\mathrm{E}$ & 0.20 \\
\hline APL_1957 & - & Lipoprotein_5 domain containing protein & S & 3.36 \\
\hline APL_1956 & - & Putative $\mathrm{N}$-methylhydantoinase $\mathrm{B} /$ acetone carboxylase, alpha subunit & S & 2.74 \\
\hline APL_1955 & $h p u B^{\#}$ & Probable hemoglobin-haptoglobin-binding protein 2 precursor & $\mathrm{P}$ & 1.63 \\
\hline APL_1954 & hpuB ${ }^{\#}$ & Hemoglobin-haptoglobin utilization protein B precusor & $P$ & 1.70 \\
\hline APL_1953 ${ }^{+}$ & hpuB ${ }^{\#}$ & Hemoglobin-haptoglobin-binding protein A precursor & P & 1.03 \\
\hline APL_1849 ${ }^{+}$ & $\| d D$ & L-lactate dehydrogenase [cytochrome] & C & 2.04 \\
\hline APL_1806 & - & hypothetical protein & S & 0.98 \\
\hline APL_ $1571^{+}$ & tonB1 & Periplasmic protein & M & 1.46 \\
\hline APL_1570 & exbB1 & Biopolymer transport protein & $U$ & 2.35 \\
\hline APL_1569 & exbD1 & Biopolymer transport protein & U & 1.77 \\
\hline APL_1568 & tbpB1 & Transferrin-binding protein 2 precursor & $P$ & 0.92 \\
\hline APL_ $1567^{+}$ & tbpA1 & Transferrin-binding protein 1; tonB dependent receptor & P & 1.24 \\
\hline APL_1566 & - & Hypothetical protein & S & 1.40 \\
\hline APL_1565 & - & Putative gluconolactonase (Glucose secondary pathway) & G & 1.42 \\
\hline APL_1564 & $x y \mid B 1$ & Sugar (Pentulose and hexulose) kinase & G & 1.20 \\
\hline APL_1523 & chuW & Probable oxygen-independent coproporphyrinogen III oxidase & $\mathrm{H}$ & 0.62 \\
\hline APL_1522 & - & Predicted nucleoside-diphosphate-sugarepimerase & MG & 0.88 \\
\hline APL_1350 & $\operatorname{teh} B$ & Tellurite resistance protein & P & 0.73 \\
\hline APL_1299 & hemR & Iron-regulated OM protein; tonB dependent receptor & P & 1.19 \\
\hline APL_ $1271^{+}$ & ndh & NADH dehydrogenase (part of oxidative phosphorylation pathway) & C & 0.37 \\
\hline APL_1265 & $\operatorname{cop} A$ & Copper-transporting P-type ATPase & P & 1.46 \\
\hline APL_1264 & - & Cation transport ATPase & P & 1.81 \\
\hline APL_1263 & - & Predicted metal-binding protein & $\mathrm{R}$ & 1.60 \\
\hline APL_1048 ${ }^{+}$ & hugZ & Putative heme utilization protein & $P$ & 2.41 \\
\hline APL_1047 ${ }^{+}$ & hgbA & Probable haemoglobin-and-haptoglobin binding protein 4 & $\mathrm{P}$ & 1.81 \\
\hline APL_1046 & lysE & Lysine exporter protein & E & 1.84 \\
\hline APL_1045 & $\operatorname{rarD}$ & Predicted permease & $\mathrm{R}$ & 0.66 \\
\hline APL_0762 & - & SAM-dependent methyltransferase & Q & 0.29 \\
\hline APL_0716 & - & Iron(III) $A B C$ transporter, permease protein & $P$ & 0.40 \\
\hline APL_0715 & - & Iron(III) transport system permease protein & P & 0.43 \\
\hline APL_0714 & FatB & ABC-type enterochelin transport system, periplasmic component & P & 0.36 \\
\hline APL_0669 & $y w b N$ & Putative iron dependent peroxidase & $P$ & 0.75 \\
\hline APL_0668 ${ }^{+}$ & - & Predicted periplasmic lipoprotein involved in iron transport & $P$ & 0.66 \\
\hline APL_0656 ${ }^{+}$ & hlyx & Fumarate/nitrate reduction transcriptional regulator & T & 0.52 \\
\hline APL_0585 & - & AcrR protein, putative HTH-type transcriptional regulator & K & 0.29 \\
\hline APL_0565 & cirA & Hypothetical ABC transporter ATP-binding protein & $\mathrm{P}$ & 0.67 \\
\hline APL_0271 $1^{+}$ & $y f e B$ & Iron (chelated) transporter, ATP-binding protein & $P$ & 0.76 \\
\hline APL_0149 & nfuA & $\mathrm{Fe} / \mathrm{S}$ biogenesis protein & O & 0.62 \\
\hline APL_0129 & $r n h B$ & $\begin{array}{l}\text { RNase HII; binds manganese; endonuclease which specifically } \\
\text { degrades the RNA of RNA-DNA hybrids (DNA synthesis pathway) }\end{array}$ & L & 0.50 \\
\hline APL_0128 ${ }^{+}$ & yfec & Putative iron transport system membrane protein & $P$ & 0.45 \\
\hline APL_0127 & $y f e D$ & Iron (chelated) transport system membrane protein & $P$ & 0.42 \\
\hline APL_0076 ${ }^{+}$ & $\operatorname{ton} B 2$ & Protein tonB & M & 0.41 \\
\hline (APL_0073 & $y d h D$ & Conserved monothiol glutaredoxin-like protein & O & 0.47 \\
\hline
\end{tabular}

* Organized according to Locus tag numbers of A. pleuropneumoniae serotype 5 in GenBank.

** Clusters of Orthologous Groups.

+ Genes in common with A. pleuropneumoniae serotype 1 [26].

\# Genes significantly differentially expressed among serotypes. 
Table 2 Genes down-regulated in A. pleuropneumoniae under iron limitation

\begin{tabular}{|c|c|c|c|c|}
\hline Locus tag & Gene & Gene function & COG** & $\begin{array}{l}\text { Ratio } \\
\text { (log2) }\end{array}$ \\
\hline$\overline{\mathrm{APL}} 1757^{+}$ & fumC & fumarate hydratase & C & -0.83 \\
\hline APL_1675 & $d m s B$ & anaerobic dimethyl sulfoxide reductase chain B & C & -2.00 \\
\hline APL_1674 ${ }^{+}$ & $d m s A$ & Anaerobic dimethyl sulfoxide reductase chain A precursor & C & -2.07 \\
\hline APL_1572 & - & Predicted membrane protein & S & -0.67 \\
\hline APL_1546 & hcp & $\begin{array}{l}\text { hydroxylamine reductase, catalyzes the reduction of hydroxylamine to } \\
\text { ammonia and water (Fe-S cluster containing protein) }\end{array}$ & C & -1.28 \\
\hline APL_1529+ & frdA & Fumarate reductase flavoprotein subunit & C & -0.90 \\
\hline APL_1528 & $\operatorname{frdB}$ & Fumarate reductase iron-sulfur subunit & C & -0.90 \\
\hline APL_1527 & frdC & Fumarate reductase subunit $C$ & C & -1.39 \\
\hline APL_1526 & frdD & Fumarate reductase subunit $D$ & C & -1.37 \\
\hline APL_1496 & & Predicted esterase & R & -0.24 \\
\hline APL_1432 & - & Putative NAD(P)H oxidoreductase & R & -0.66 \\
\hline APL_1431 $1^{+}$ & napF & Ferredoxin-type protein & C & -1.23 \\
\hline APL_1430 & napD & putative periplasmic nitrate reductase protein & P & -1.66 \\
\hline APL_1429 & napA & Periplasmic nitrate reductase & C & -1.14 \\
\hline APL_1428 & napG & Quinol dehydrogenase periplasmic component & C & -1.39 \\
\hline APL_1427 & napH & Quinol dehydrogenase membrane component & C & -1.14 \\
\hline APL_1426 & $n a p B$ & Nitrate reductase cytochrome c-type subunit & C & -1.60 \\
\hline APL_1422 & napC & Nitrate/TMAO reductase & C & -1.42 \\
\hline APL_1379 & $\operatorname{mauG}^{\#}$ & Cytochrome c peroxidase & $P$ & -1.95 \\
\hline APL_1367 & $\mathrm{ccmF}$ & Cytochrome c-type biogenesis protein & O & -0.54 \\
\hline APL_1337 & hypG & Hydrogenase maturation factor & O & -0.68 \\
\hline APL_1336 & hybE & Hydrogenase 2-specific chaperone & S & -1.00 \\
\hline APL_1335 & hyad & $\mathrm{Ni}$, Fe-hydrogenase maturation factor & C & -0.99 \\
\hline APL_1334 & hyaB & $\mathrm{Ni}$, Fe-hydrogenase I large subunit & C & -1.06 \\
\hline APL_1333 & hybB & Putative cytochrome b subunit of the hydrogenase 2 & C & -1.17 \\
\hline APL_1332 & hybA2 & Fe-S-cluster-containing hydrogenase components 1 & C & -1.95 \\
\hline APL_1331 & hya $A^{\#}$ & $\mathrm{Ni}$, Fe-hydrogenase I small subunit & C & $-2,51$ \\
\hline APL_1328 & hybD ${ }^{\#}$ & Hydrogenase maturation factor & O & -1.90 \\
\hline APL_1327 & hyp $B^{\#}$ & Hydrogenase nickel incorporation protein & OK & -2.1 \\
\hline APL_1316 & dcuB2 & Anaerobic C4-dicarboxylate membrane transporter & $\mathrm{R}$ & -0.78 \\
\hline APL_1253 & - & Di- and tricarboxylate transporter & $P$ & -0.83 \\
\hline APL_1216 & luxS & S-ribosylhomocysteine lyase & T & -0.39 \\
\hline APL_1213 & - & Predicted phosphatase/phosphohexomutase & $\mathrm{R}$ & -1.21 \\
\hline APL_1237 & - & Possible integral membrane sulfate transporter & P & -0.64 \\
\hline APL_1162 & - & Predicted iron-dependent peroxidase & P & -0.41 \\
\hline APL_1156 & citT & Di-and tricarboxylate transporter & P & -1.20 \\
\hline APL_1129 & cytB562 & Soluble cytochrome b562 & C & -0.48 \\
\hline APL_1124 & $p f k A$ & 6-phosphofructokinase & G & -0.37 \\
\hline APL_1086 & ompW & OM protein ompW precursor & M & -1.53 \\
\hline APL_1036 & $p f l B$ & Formate acetyltransferase & C & -0.38 \\
\hline APL_1011 & adh2 & $\begin{array}{l}\text { Alcohol dehydrogenase, class IV/NAD-dependent aldehyde } \\
\text { dehydrogenases }\end{array}$ & C & -1.24 \\
\hline APL_0966 & - & Putative transport protein & R & -0.71 \\
\hline APL_0895 & $f d n l$ & Formate dehydrogenase, gamma subunit & C & -1.15 \\
\hline APL_0894 ${ }^{+}$ & $f d x H$ & Formate dehydrogenase, iron-sulfur subunit & C & -1.17 \\
\hline APL_0893 ${ }^{+}$ & $f d x G$ & Formate dehydrogenase, nitrate-inducible, major subunit & C & -1.01 \\
\hline APL_0892 & $f d x G$ & Formate dehydrogenase, nitrate-inducible, major subunit & C & -1.18 \\
\hline APL_0857 & $s d a A^{\#}$ & L-serine dehydratase (gluconeogenesis) & $\mathrm{E}$ & -1.00 \\
\hline APL_0856 & $s d a C^{\#}$ & serine transporter & E & -1.58 \\
\hline
\end{tabular}


Table 2: Genes down-regulated in A. pleuropneumoniae under iron limitation (Continued)

\begin{tabular}{|c|c|c|c|c|}
\hline APL_0780 & $\operatorname{lrg} A 2^{\#}$ & Putative effector of murein hydrolase LrgA & $\mathrm{R}$ & -1.11 \\
\hline APL_0779 & - & Putative effector of murein hydrolase & M & -0.90 \\
\hline APL_0723 & $\operatorname{tgt}$ & Queuine tRNA-ribosyltransferase & $J$ & -0.15 \\
\hline APL_0688 ${ }^{+}$ & torZ & Trimethylamine-N-oxide reductase precursor & C & -1.61 \\
\hline APL_0607 ${ }^{+}$ & $n f n B$ & Putative $\mathrm{NAD}(\mathrm{P}) \mathrm{H}$ nitroreductase & C & -0.54 \\
\hline APL_0446 & ykgE & Putative dehydrogenase subunit, Fe-S oxidoreductase & C & -2.63 \\
\hline APL_0445 & ykgF & Iron-sulfur electron transport protein & C & -1.79 \\
\hline APL_0444 & engA & Putative GTP binding protein & S & -1.10 \\
\hline APL_0416 & - & N-acetyl-D-glucosamine kinase & KG & -0.36 \\
\hline APL_0155 & ngrF & Na+-translocating NADH-ubiquinone oxidoreductase subunit F & C & -0.37 \\
\hline APL_0154 & nqre & Na+-transporting NADH-ubiquinone oxidoreductase subunit E & C & -0.35 \\
\hline APL_0153 & nqrD & Na+-translocating NADH-ubiquinone oxidoreductase subunit D & C & -0.47 \\
\hline APL_0151 $1^{+}$ & $n q r B$ & Na+-translocating NADH-ubiquinone oxidoreductase subunit B & C & -0.40 \\
\hline APL_0150 & nqra & Na+-translocating NADH-ubiquinone oxidoreductase subunit A & C & -0.46 \\
\hline APL_0103 & $n r f D^{\#}$ & Nitrate reductase, transmembrane protein & $P$ & -1.51 \\
\hline APL_0101 ${ }^{+}$ & $n r f B^{\#}$ & Cytochrome c nitrite reductase pentaheme subunit & C & -2.17 \\
\hline APL_0100 & $n r f A^{\#}$ & $\begin{array}{l}\text { Nitrate reductase, cytochrome c552, catalyzes the formate-dependent } \\
\text { reduction of nitrite to ammonia; }\end{array}$ & $P$ & -2.34 \\
\hline
\end{tabular}

* Organized according to Locus tag numbers of A. pleuropneumoniae serotype 5 in GenBank.

** Clusters of Orthologous Groups.

${ }^{+}$Genes in common with A. pleuropneumoniae serotype 1 [26].

\# Genes significantly differentially expressed among serotypes.

Orthologous Groups (COGs, http://www.ncbi.nlm.nih. gov/COG, [39]), there was a striking difference in the distribution of functional groups between the up- and down-regulated genes (Figure 3 ). Nearly half $(47 \%)$ the up-regulated genes belonged to the "Inorganic ion transport and metabolism" category while this group of proteins only represented $12 \%$ of the down-regulated genes. The down-regulated genes mainly (57\%) belonged to the "Energy production and conversion" category, a group which only constituted $4.5 \%$ of the up-regulated genes. In general, we observed a pattern of gene expression very similar to previous observations of transcriptional response to iron limitation in Pasteurellaceae: an increased uptake of iron via the mobilization of irontransport genes and siderophores and a decrease in iron consumption by down-regulation of non-essential iron consuming proteins, mostly genes involved in anaerobic metabolism [26-29].

Genes up-regulated under growth in iron-depleted media Not surprisingly, many of the up-regulated genes in this study were related to iron homeostasis (Table 1); at least $60 \%$ of these were previously identified in A. pleuropneumoniae serotype 1 under similar conditions by Deslandes et al. [26]. Some genes were homologous to iron-regulators commonly found in the Pasteurellaceae group or in Gram-negative bacteria, and known to be of major importance to iron sequestration of the host.
Among these were the tonB1-exbB1-exbD1 complex, universally found in Gram-negative bacteria [25,40], and the two co-regulated transferrin receptor genes $t b p B 1$ and tbpA1 [21,23]. TonB2, but not exbB2-exbD2, was up-regulated. In accordance with previous observations, the up-regulation of ton $B 2$ was lower than in $\operatorname{ton} B 1$ ( $\log 2$ ratios of 0.41 and 1.46, respectively) [24]. Also highly expressed under iron restriction were $\mathrm{OM} \mathrm{Hb}$ receptor $h g b A$ and the putative haem utilization gene, hugZ $[25,26]$. As in most transcriptional profiling studies of Pasteurellaceae species under iron deprivation, members of the $y f e$ system likewise showed up-regulated transcription [26-29].

\section{Putative hemoglobin and haem uptake genes}

As previously observed in A. pleuropneumoniae serotype 1 , iron depletion resulted in up-regulation of a putative tonB-dependent haem receptor (APL_1299) [26]. APL_1299 encodes a protein with significant similarity to tdhA/hemR/huxC genes of other Pasteurellaceae species [41]. This gene appears to be important for heme-hemopexin uptake during host adaptation in $H$. influenzae and P. multocida [42]. APL_1299 is probably of less significance in A. pleuropneumoniae, where the $h g b A$ gene appears to be sufficient for heme/iron acquisition from the mammal host [25]. A more interesting virulence candidate is the tellurite resistance gene, tehB. TehB increased its expression during growth in iron restrictive media in all six serotypes of $A$. pleuropneumoniae, as well 

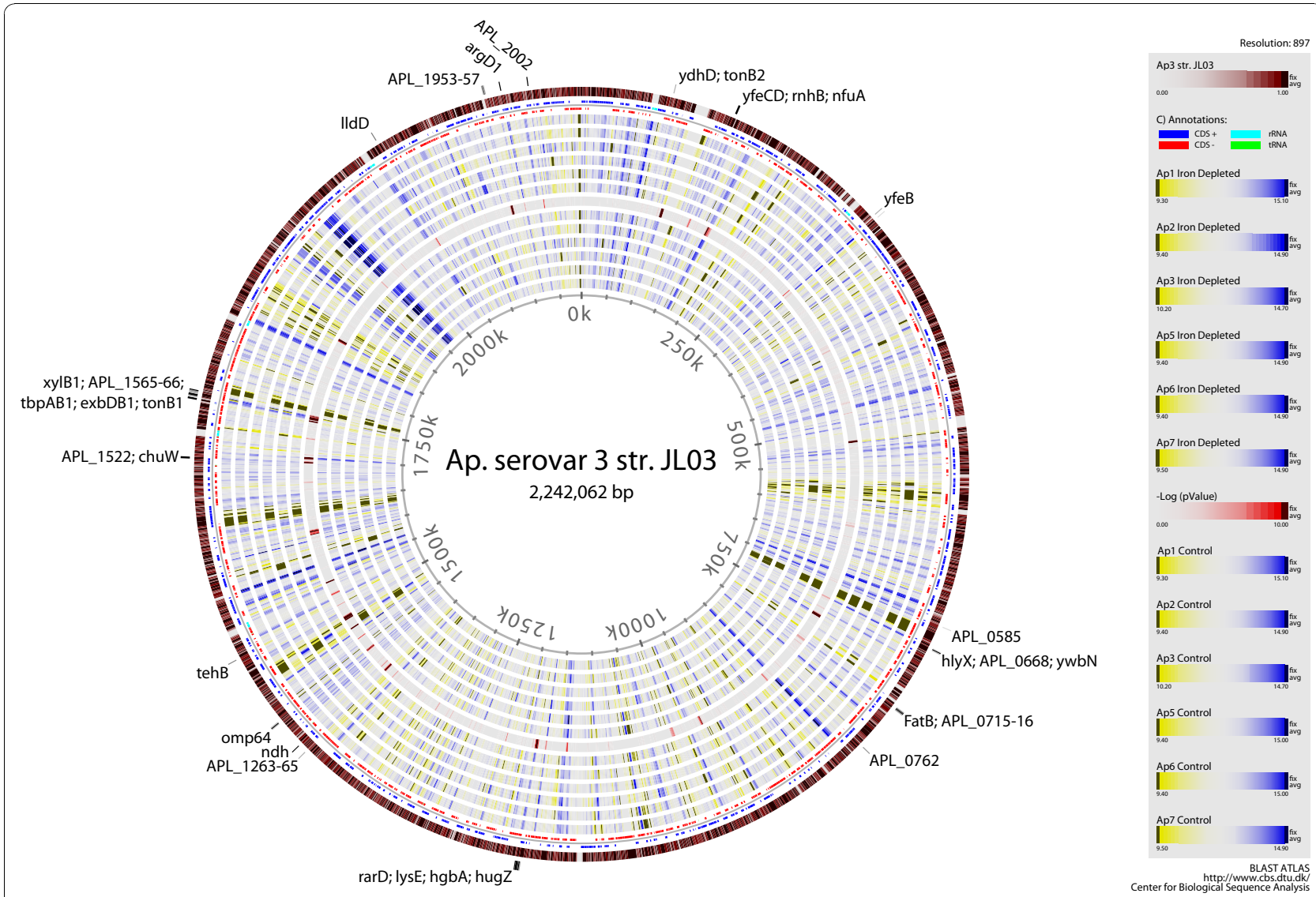

Figure 2 Genome BLAST atlases of A. pleuropneumoniae expression patterns. A. pleuropneumoniae 3 str. JL03 is the reference genome and is compared to the remaining five serotypes, including controls (K) (rings 1 to 6 from center) and iron depleted cultures (JH) (rings 8 to 13 from center). The $\mathrm{p}$ values of the expression differences between control and iron depleted cultures are included (ring 7 from centre). The positions of the ORFs displaying significant up-regulation under iron restriction are marked.

as in P. multocida and in H. influenzae [26,27]. In $H$. influenzae, tehB is involved in both resistance to oxidative damage and haem uptake/utilization, and is an important virulence factor in this organism in an animal model of invasive disease [43]. Further studies are needed to determine whether tehB is also of importance to iron-sequestration in A. pleuropneumoniae.

A new potential iron acquisition system identified by Deslandes et al. [26] was also up-regulated under iron limited conditions in this study. The three putative open reading frames (ORFs), APL_1953 to APL_1955, all displayed between $50 \%$ to $55 \%$ homology with the tonBdependent haemoglobin-haptoglobin receptor, $h p u B$, of $N$. meningitidis [44]. In N. meningitidis, slip-strand mispairing is the cause of phase variation in the expression of hpuAB [44]. In the ORF APL_1953 of A. pleuropneumoniae, we observed serotype related sequence variation in the form of a $71 \mathrm{bp}$ insertion/deletion region, situated just before a 42 bp sequence of high GC content (62\% GC in serotype 5 against a normal average of $41 \%$ )
(Figure 4). Such GC rich sequences can be regions of high recombination [45]. In serotypes 2,5 , and 6 , the 71 bp were missing, whereas the sequence was present in serotypes 1, 3, and 7. We PCR amplified and sequenced the part of APL_1953 harboring the variable region in all six serotypes. This confirmed that the observed differences were not due to assembly error in the published genomes. In the short version, APL_1953 codes for a putative protein of $19.7 \mathrm{kDa}$ and in the long version a $26.7 \mathrm{kDa}$ sized protein. Judging from our results, APL_1953 appeared to be expressed in all the included A. pleuropneumoniae serotypes. Such an insertion/deletion event may have an important role in transitions between commensalism and pathogenicity [45]. In this case, both variants of the APL_1953 gene included a high-virulent serotype. Consequently, it is doubtful if this particular region is related to virulence. Still, it would be interesting to examine the possible effect of the insertion/deletion region with regard to protein function. 


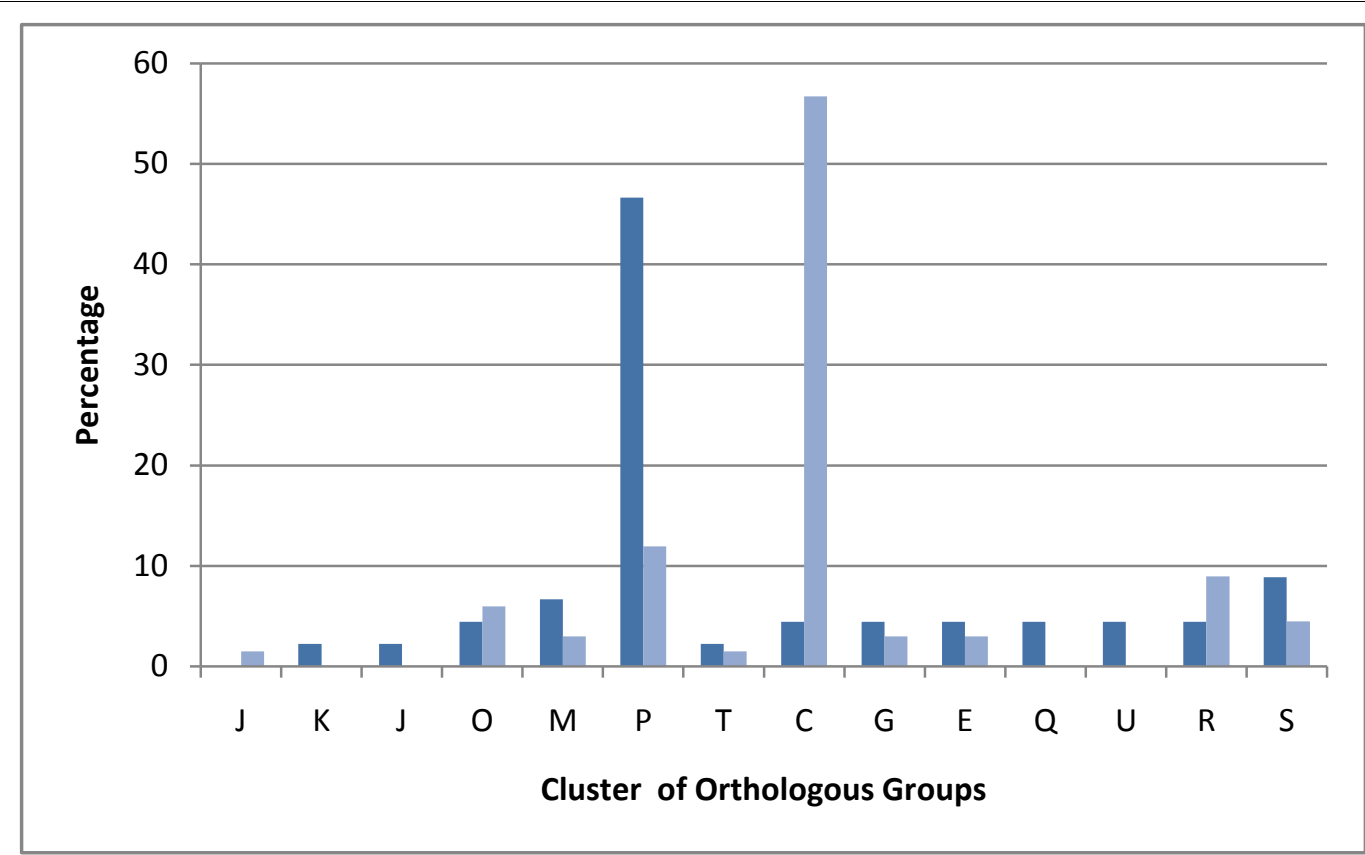

Figure 3 Distribution of significantly regulated genes classified according to the Clusters of Orthologous groups (COGs). Dark blue bars: up-regulated genes, light blue bars: down-regulated genes. J: translation, ribosomal structure and biogenesis, K: transcription, L: DNA replication, recombination, and repair, O: posttranslational modification, protein turnover, chaperones, $\mathrm{M}$ : cell envelope biogenesis, outer membrane, P: inorganic ion transport and metabolism, T: signal transduction mechanisms, C: energy production and conversion, G: carbohydrate transport and metaholism, E: amino acid transport and metabolism, Q: secondary metabolites biosynthesis, transport, and catabolism, U: intracellular trafficking, secretion, and vesicular transport, R: general function prediction, only, S: function unknown.

The three $h p u B$ ORFs also displayed serotype-specific transcriptional variations in response to iron levels of the media. Here, the most intriguing observation was the low expression of all three genes in serotype 3 , which, is considered one of the least virulent A. pleuropneumoniae serotypes (Figure 5A) [4,18]. In the qPCR analysis, serotype 3 was the only serotype in which none of the three ORFs were significantly up-regulated during iron deprivation (Figure 5B). For the remaining serotypes, we observed no correlation between level of pathogenesis and degree of expression. Serotype 2, for example, was only significantly up-regulated in APL_1954 and in the moderately virulent serotype 6, all three genes were highly up-regulated. As previously mentioned, infection experiments have shown that differences in pathogenic potential also exists within serotypes [17]. Therefore comparisons of strains of the same serotype which have experimentally been determined to be of differential virulence might elucidate the role of these ORFs in A. pleuropneumoniae.

Srikumar et al. [25] have shown that the function of $h g b A$ as $\mathrm{Hb}$ receptor of $A$. pleuropneumoniae cannot be replaced. Still, considering the above mentioned findings, it is tempting to speculate that the $h p u B$ genes are of some importance to iron regulation and constitute potential virulence factors of $A$. pleuropneumoniae. Recent observations support these assumptions. Along with a number of iron acquisition-associated genes of documented importance for virulence, e.g. $\operatorname{ton} B 1$ and $\operatorname{ton} B 2$, the $h p u B$ gene cluster has been shown to be regulated by the global regulator 'fumerate and nitrate reduction regulator' (FNR) homologue, hlyX [46]. Furthermore, a study by

\section{5'TCGCTTTATGCGCGTTACGGTAACTTTAATACCTCACGTTTAACTATTGATC CCGAGTTAGTAACAGGGATTGATATTGTACGTGGTTTGGATTCATTTACCAC CGGTAGCGGTTCGCTTGGCGGCGGAGTGAATTATCGTACTTTAGAT-3'}

Figure 4 Variable region of ORF APL_1953 illustrated in serotype 7. Red text: region with high GC concentration (57\% in serotype 7). Underscored text: region missing in A. pleuropneumoniae serotypes 2, 5, and 6 . 
Auger et al. [47] indicated some role of APL_1955 during infection. In a cell infection model, the authors found this gene to be up-regulated in A. pleuropneumoniae adhering to porcine lung cells when compared to nonattached (planktonic) bacteria from the same media [47]. Further research is needed to clarify the importance of the $h p u B$ gene cluster.

Situated just next to the $h p u B$ genes, but transcribed in the opposite direction were the ORFs APP_1957 and APP_1956. Both genes are of unknown function. APP_1957 displayed a putative lipoprotein_5 containing domain. APP_1956 was homologous to the carboxylase alpha subunit of $\mathrm{N}$-methylhyantoinase $\mathrm{B} /$ acetone. Like Deslandes et al. [26], we observed these genes to be both highly up-regulated in response to iron deprivation in all serotypes. In fact, with $\log _{2}$ ratios of 3.36 and 2.74, respectively, they were the two most highly up-regulated genes of this study (Table 1).

\section{Known and putative siderophores of A. pleuropneumoniae}

The high affinity of OM receptors for their corresponding siderophore complexes, allow bacteria to more efficiently scavenge ferri-siderophores from their surroundings [19]. A. pleuropneumoniae is able to use exogenous hydroxamate and catecholate siderophores for promotion of growth [48]. Presently, only one siderophore receptor, the ferric hydroxamate specific, fhuA, has been described for this microorganism [31]. Besides the $f h u$-system, genome comparisons among virulent and commensal species of Pasteurellaceae indicate the presence of a second siderophore uptake system in $A$. pleuropneumoniae [41]. This possible ABC-type cobala$\mathrm{min} / \mathrm{F}^{3+}$ siderophore operon consists of a periplasmic component (APL_0714) and an ATPase component (APL_0717) homologous to the siderophore binding protein $\mathrm{fec} B$, and the ATP-binding protein, $f e c E$, of $P$. multocida, respectively. The two permease components (APL_0715 and APL_0716), constitute the trans-membrane subunits of this putative siderophore transport system [41]. We observed an increased expression of APL_0714 to APL_0716 in response to iron deprivation in a seemingly co-regulated manner (Table 1). Under similar conditions, APL_0714 and APL_0717 were upregulated in serotype 1 [26]. The increased expression during iron deprivation and the close homology of APL_0714 to APL_0717 with siderophore family transporters of other Pasteurellaceae support the hypothesis of a second siderophore acquisition system in $A$. pleuropneumoniae.

We also identified a third putative A. pleuropneumoniae siderophore receptor, ORF APL_0565, which was transcriptionally active under iron limited growth conditions in all six serotypes. This hypothetical tonB-dependent, $\mathrm{ABC}$ transporter ATP-binding protein displays 83\%, homology with the cirA genes of Actinobacillus minor and shares $49 \%$ identity with the putative OM ferric siderophore of $N$. meningtidis. The estimated molecular weight of the A. pleuropneumoniae cirA protein, $72.6 \mathrm{kDa}$, is close to the $74 \mathrm{kDa}$ size of the orthologous protein in Escherichia coli. In E. coli, the cirA gene was one out of six OM proteins identified as $\mathrm{Fe}^{3+}$ siderophore receptors regulated by fur and iron concentrations [49-51]. One of the most effective ferric iron chelating compounds known is enterobactin, the chatecholate type siderophore of $E$. coli and several other bacteria [52]. As previously mentioned, A. pleuropneumoniae is able to use catecholate siderophores for promotion of growth [48]. Possibly the fec-like operon and the hypothetical $\operatorname{cir} A$ protein encode the siderophore receptors responsible for uptake of this iron-chelator in A. pleuropneumoniae. Contrary to the $f h u$-system, whose regulation is iron-independent [32], the putative catecholate receptors appear to be iron-repressible.

\section{Other iron uptake systems}

The iron and fur repressed operons $y c d N O B$ of E. coli and $y w b L M N$ of Bacillus subtillis are predicted elemental iron uptake systems orthologous to the copper oxidase-dependent $\mathrm{Fe}$ (III) uptake system, Ftrp/Fet3p, of Saccharomyces cerevisiae [53]. In B. subtillis, ywbLMN appears to be involved in the uptake of free ferric iron [54]. An ycdNOB-ywbLMN-like fur repressed irontransport system may also be present in A. pleuropneumoniae, represented by the ORFs APL_0670, APL_0669, and APL_0668. All three ORFs were upregulated in $A$. pleuropneumoniae serotype 1 under iron limitation [26]. We found only the last two ORFs to be up-regulated in all the included serotypes under similar growth conditions. APL_0669 encoded a putative peroxidase $Y w b N$ precursor. APL_0668, a putative periplasmic lipoprotein involved in iron transport, is $58 \%$ identical to the $y c d O$ of Gemella haemolysans. By analogy of the well-characterized Saccharomyces cerevisiae Ftrp/Fet3p system, it has been suggested that $y w b L M N$ functions as a $\mathrm{Fe}(\mathrm{III})$ permease [54]. In $B$. subtilis, the $y w b L M N$ iron uptake system was required for growth in iron-limited medium lacking citrate, and in $E$. coli the $y c d N O B$ proteins function as an additional ferrous iron-uptake systems $[54,55]$. The functional role of the putative operon, $y w b L M N$, of $A$. pleuropneumoniae is presently unknown.

\section{Other up-regulated genes}

Also up-regulated in the iron depleted bacteria was a potential co-regulated operon consisting of the coppertransporting P-type ATPase, copA gene (APL_1265), a putative cation transport ATPase (APL_1264), and a predicted metal-binding protein (APL_1263). In eukaryotes, several interdependent connections between copper and iron homeostasis have been described. Knowledge of such processes in bacterial systems is still 


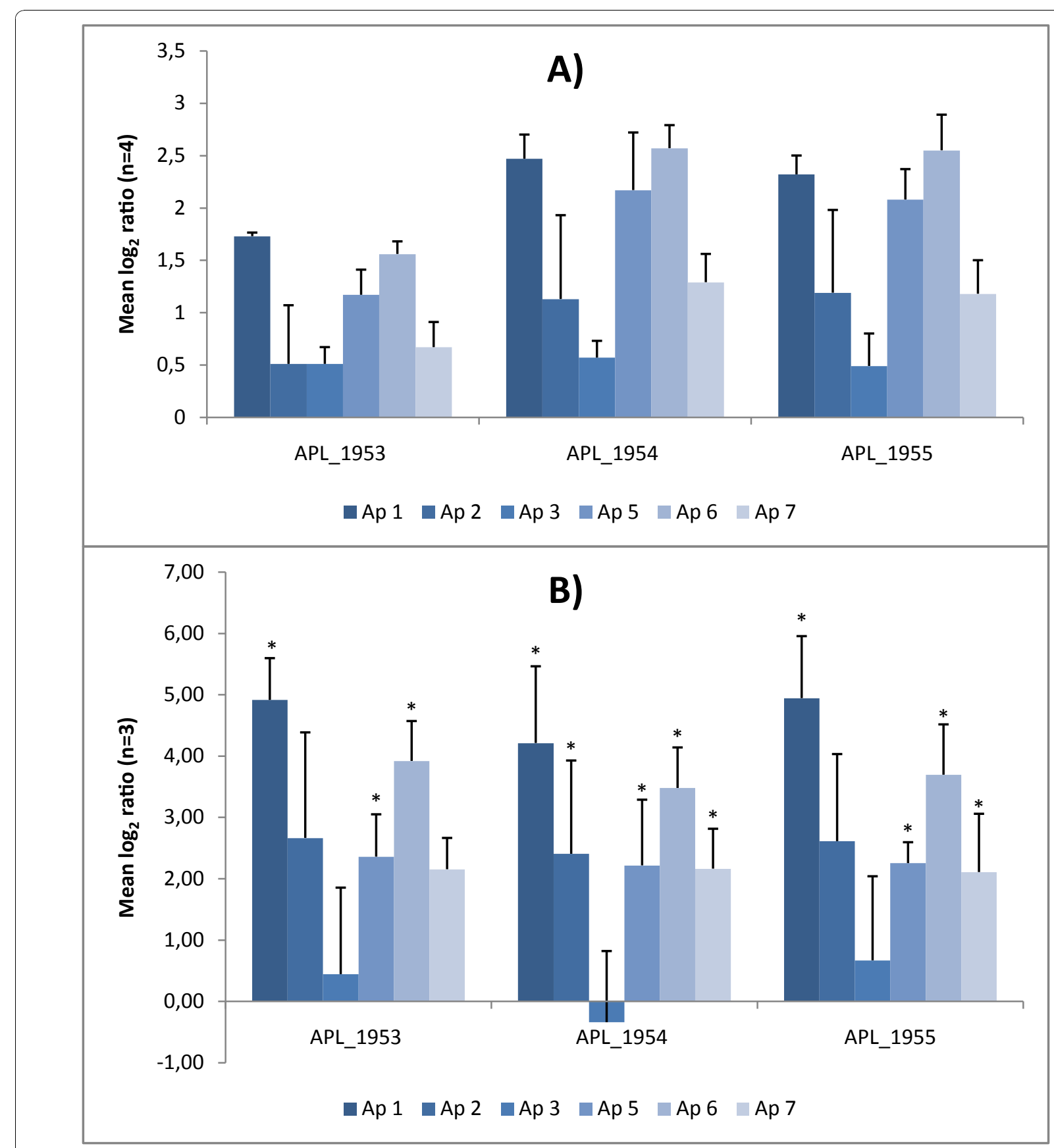

Figure 5 Serotype specific transcriptional up-regulation in response to iron depletion. Individual mean $\log _{2}$ expression ratios for the three hpuB ORFs, APL_1953 to APL_1955 in the six included A. pleuropneumoniae serotypes: (A) obtained with microarray analysis, (B) obtained with qPCR analysis. Hinges represent the $95 \%$ confidence intervals. The asterisks indicate statistical significant up-regulation $(P<0.05)$ as determined by simple statistical randomization test in REST [71].

limited [56]. In E. coli, 2,2'-dipyridyl supposedly only effects iron and not the copper and magnesium levels of the bacterial cell [57]. Still, we have reason to believe that the up-regulation of at least the $\operatorname{cop} A$ in serotype 6 may be an artifact introduced by this high affinity chelator. Primarily because the qPCR analysis, testing the possible effect of 2,2'-dipyridyl, indicated that this regulatory event was un-related to iron deficiency. Secondly, in a similar study, the copA gene of Staphylococcus aureus was expressed in the media but not in vivo [58]. Finally, none of the above mentioned three genes were up-regulated in A. pleuropneumoniae serotype 1 when EDDHA was used to obtain iron restricted conditions [26]. 
We also saw an up-regulation of the Fe/S biogenesis protein, $n f u A$. In $E$. coli, $n f u A$ is required for maturing $\mathrm{Fe} / \mathrm{S}$ proteins under oxidative stress and iron starvation [59]. Overall, observations from studies involving E. coli and other bacteria seem to point towards a general role for the ubiquitous bacterial protein $n f u A$ in $\mathrm{Fe} / \mathrm{S}$ protein folding under stress conditions [59].

Some of the up-regulated genes of the microarray were not directly related to iron-homeostasis, but were situated next to known or putative iron regulators and displayed similar expression ratios. The position and the seeming co-regulation of these ORFs indicate some indirect involvement in iron homeostasis. For example, three loci immediately downstream of the $t b p A 1$ gene, APL_1566 to APL_1564, were all transcribed in the same direction and up-regulated to a similar extend as the $t b p B A$ genes (Table 1). The $x y l B 1$ gene (APL_1564), encoding pentolose and hexulose kinase, was also upregulated in $A$. pleuropneumoniae serotype 1 and $M$. haemolytica under iron-deprivation [26,29].

The fumerate and nitrate reduction regulator (FNR) homologue, $h l y X$ has a global regulatory role in $A$. pleuropneumoniae where it induces the expression of genes involved in anaerobic metabolism and simultaneously represses genes involved in aerobic metabolism [46]. Also the expression of the iron acquisition-associated genes, $\operatorname{frp} B$, the $\operatorname{ton} B 1$ and $\operatorname{ton} B 2$, and the newly described putative $h p u B$ cluster were found to be positively regulated by $h l y X$ under anaerobic conditions [46]. In this and previous studies of Pasteurellaceae [26,27], the gene regulations under iron restricted condition were not completely in accordance with the expected FNR regulation. In A. pleuropneumoniae and P. multocida, the $h l y X$ gene was up-regulated while genes that are normally transcriptionally activated by $h l y X$ were down-regulated (see below). Hly $X$ is important but not essential to virulence and other not-yet-identified regulators may be involved in gene regulation under anaerobic conditions [60].

\section{Genes down-regulated under iron restriction}

In agreement with observations in A. pleuropneumoniae serotype $1, P$. multocida, and $M$. haemolytica [26,27,29], more than half of the 67 down-regulated genes under iron shortage belonged to the COG group "energy production and conversion". The repressed genes were the main cellular iron consumers, mostly genes coding for metabolic enzymes dependent on Fe-S clusters or other iron cofactors e.g. hydroxylamine reductase, cytochrome c peroxidase, and the fumerate reductase operon (Table 2 ). As for deducting any hypothesis regarding difference in virulence among serotypes, the genes which displayed significant serotype related down-regulation in response to iron limitation were not very useful (genes marked with a number sign in Table 2). For all the 9 genes, a low virulent (serotype 3 ) and a high virulent (serotype 5) serotype seemed to be the least repressed.

Many down-regulated genes coded for proteins involved in anaerobic metabolism, some of which are known to be regulated by one or both of the two important anaerobic regulators, $h l y X$ and anoxic redox control protein A $(\operatorname{arc} A)[46,61]$. Genes/operons down-regulated in this study and expected to be controlled by hlyX were: 1) terminal reductases, transferring respiratory chain electrons to alternative electrons acceptors: dimethyl sulfoxide reductase $(d m s B A)$, periplasmic nitrate reductase (napFDAGHBC), and the TMAO reductase (tor $Y Z), 2$ ) genes encoding enzymes involved in the oxidation of high-energy substrates e.g. the $\mathrm{Ni} / \mathrm{Fe}$ cofactor dependent hydrogenases (hyaAB and hybAB).

Although we observed no up-regulation of $\operatorname{arc} A$, a number of genes know to be controlled by $\operatorname{arc} A$ were also differentially expressed in this study [61]. Genes negatively regulated by $\operatorname{arc} A$ and likewise down-regulated in this study were: the OM protein precursor $(\operatorname{omp} W)$, the formate dehydrogenase genes $(f d n I$ and $f d x H G)$, the putative dehydrogenase subunit $(y k g E)$, the putative Fe-S electron transport protein $(y k g F)$, and the nitrate reductase operon $(n r f D B A)$. As with the $h l y X$ regulator, the expression pattern of some genes did not concur with the expected pattern of $\operatorname{arcA}$ regulation [61]. For example, the genes encoding L-lactate dehydrogenase $(l l d D)$ and a putative oxygen-independent coproporphyrinogen III oxidase $(c h u W)$, both expected to be depressed by $\operatorname{arcA}$, were up-regulated under irondeprivation in A. pleuropneumoniae. Likewise, a number of genes, the anaerobic dimethyl sulfoxide chain precursors $(d m s A B)$, the serine dehydratase/transporter protein genes $(s d a A C)$, and a putative effector of murein hydrolase $(\operatorname{lrf} A)$ under positive regulation of $\operatorname{arc} A$, were all down-regulated in this experiment.

Clearly $h l y X$ and $\operatorname{arc} A$ were not the main regulators in A. pleuropneumoniae under iron starvation. Besides the discrepancies just described, far from all the down-regulated metabolic genes, e.g. fumarate reductase genes ( frd $A B C D)$ and the $\mathrm{Na}$-translocating NADH-ubiquinone oxireductase subunits (nqrFEDCBA) have been proven to be regulated by $h l y X$ and $\operatorname{arc} A$ [61]. As previously mentioned, an essential role of ryhB in iron metabolism has been demonstrated in E. coli, Vibrio cholera and a number of other bacteria [62]. The ubiquitous RNA-binding protein, Hfq is a key factor in regulations by sRNAs in bacteria [35]. In E. coli ryhB sRNA acts as an Hfq-dependent regulator of the acquisition and storage of iron [63]. Although not yet proven for $A$. pleuropneumoniae or other Pasteurellaceae, the recent discovery of Hfq homologues in A. pleuropneumoniae, $P$. multocida, and $H$. influenza makes it more likely that 
sRNAs participate in controlling iron metabolism in members of this family [35]. Furthermore, the overall down-regulatory response to iron limitation, observed in this and previous studies in Pasteurellaceae, fits well with the concerted actions of fur and rhyB described in E. coli [63]. Fur inactivation enables the expression of the sRNA regulator, ryhB, which then limits the usage of iron to crucial proteins by repression of as many non-essential iron-using proteins as possible [20].

\section{Conclusions}

By studying the intra-species variation in the transcriptional response of $A$. pleuropneumoniae to iron limitation, we identified a set of core genes important to the iron adaptive response of this organism. Not surprisingly, these included known virulence factors such as the $t o n B$-system, $t b p B A$ and $h g b A$, but also a number of newly described potential iron acquisition genes previously identified in $A$. pleuropneumoniae serotype 1, e. g. the putative hemoglobin-haptoglobin binding proteins and the $y f e$-system [26]. We confirmed the up-regulation of the latter genes in an additional five serotypes of $A$. pleuropneumoniae under iron limitation. Not previously observed in A. pleuropneumoniae was the up-regulation of a putative siderophore, $\operatorname{cir} A$. The $h p u B$ cluster proved to be interesting for several reasons. Firstly, all three genes displayed serotype specific expression under iron limitation. Of the six serotypes, serotype 3 was the only variant in which none of the three ORFs were significantly up-regulated under iron deprivation. Serotype 3 is also considered to be one of the least virulent serotypes of A. pleuropneumoniae. Secondly, in ORF APL_1953 a variable region was identified which differentiated serotypes 2, 5 and 6 from serotypes 1, 3 and 7. The gene was expressed in all serotypes. Except for serotype 3, we could not directly correlate the observed variances in the $h p u B$ ORFs with serotype related differences in pathogenesis. Still, it would be interesting to study further the implications of these divergences in gene expression and length and to determine the role the hpuB gene complex concerning iron acquisition and virulence in A. pleuropneumoniae. In all, the combined effect of iron-depletion and serotype proved to be modest, indicating that serotypes of both medium and high virulence at least in vitro are reacting almost identical to iron restriction. This is perhaps not very surprising, considering the functional importance of the core genes involved in iron regulation.

Attesting to the quality of the array were: 1) the concordance of gene regulation within the operons, 2) the agreement of results between this and previous transcriptional studies of Pasteurellaceae under conditions of iron limitation [26-29], and 3) the high correlation between the microarray and $\mathrm{qPCR}$ expression ratios.
Consequently, the results attest the utility of this novel pan-genomic $A$. pleuropneumoniae microarray. The design of this array is publicly available and will hopefully be applied for multiple purposes of serotype comparisons in the future.

\section{Methods}

\section{Bacterial strains and growth conditions}

The following strains of $A$. pleuropneumoniae were used in this investigation: Serotype 1 (4074), serotype 2 (4226), serotype 3 (1421), serotype 5b (L20), serotype 6 (7712640), serotype 7 (WF87). For the iron depletion study, an overnight culture was diluted 1:10 in brain heart infusion broth supplemented with $0.03 \%$ NAD (Sigma-Aldrich, Copenhagen, Denmark) and incubated until the optical density at $660 \mathrm{~nm}$ was 0.6 , representing the exponential growth phase. The culture was split into two 10-ml portions. Iron-depleted conditions were established in one of the flasks by addition of $300 \mu \mathrm{M}$ 2,2'-dipyridyl (Sigma-Aldrich). For serotype 2 and 6, iron repletion experiments were also performed: to a third 2,2'-dipyridyl containing flask, $300 \mu \mathrm{M}$ ammonium iron(II) sulfate hexahydrate (Sigma-Aldrich) was added. Next, the cultures were grown under shaking at $37^{\circ} \mathrm{C}$ for $30 \mathrm{~min}$, after which one volume of RNAlater stabilization reagent (Ambion, Cambridgeshire, United Kingdom) was added to the cultures. Samples were harvested by centrifugation, immediately resuspended in one volume of PBS and 5 volumes of RNAlater. Samples were stored at $4^{\circ} \mathrm{C}$ until extraction. For each serotype, four experiments were performed on different days.

\section{RNA isolation and reverse transcription}

Total RNA was isolated from $1.5-\mathrm{ml}$ portions of bacterial samples by using an RNeasy mini kit (QIAGEN, Hilden, Germany) as described by the manufacturer. Genomic DNA was eliminated by RNase-free DNase I treatment during the isolation procedure. After RNA extraction, the material was further treated by TURBO ${ }^{\mathrm{TM}}$ DNase, according to the protocol provided by the manufacturer (Ambion). The RNA concentration and quality were measured by NanoDrop (Thermo Scientific, Wilmington, DE, USA) and Agilent 2100 Bioanalyzer (Agilent Technologies, Santa Clara, CA, USA), respectively. Quality requirements were: A260/A280 $\geq 1.8$ and A260/A230 $\geq 1.8$ and RIN $\geq$ 7.5. Samples not meeting this standard were discarded and new extractions performed. Exceptions to this rule were serotype 5 , where the RIN numbers consistently remained between 5.5 and 6 , and serotype 6 , generally displaying RIN numbers just below 7 .

\section{Designing the custom array}

The arrays used in this project were based on the NimbleGen 12-plex platform, officially released in a news 
statement on Nov. 19, 2008. The custom probe set for the arrays was build around a set of 7 core genomes representing all publically available $A$. pleuropneumoniae and Actinobacillus succinogenes genomes in GenBank and RefSeq [PMID: 18073190]. These included A. pleuropneumoniae serotype 1 str. 4074 [GenBank: AACK00000000], serotype 2 str. 4226 [GenBank: ADXN00000000], serotype 3 str. JL03 [GenBank: NC 010278], serotype 5b str. L20 [GenBank: NC 009053], serotype 6 str. Femo [GenBank: ADXO00000000], and serotype 7 str. AP76 [GenBank: NC 010939]. [64-66]. In total, 15018 target genes were identified from these data.

\section{Constructing the Target Gene Set}

All genes were aligned all-against-all and any two genes sharing more than $90 \%$ identity over the full length of the shortest sequence were connected together into gene networks. Representatives from each gene network were selected using the algorithm of Hobohm et al. [67] for maximizing the size of the selected set. This algorithm eliminates redundancy in a network through the removal in order of the most highly connected members. This produced a set of 4876 Actinobacillus target genes. In total, each array consisted of 130.194 active probes excluding NimbleGen control probes. Each gene was covered by an average of 26.7 probes. The design of this array is publicly available at NimbleGen (091013_DTU_Actino_xRNA).

\section{Probe Selection for Target Genes}

Probes for the target gene set were selected using the OligoWiz program $[68,69]$ applying the following weighting of the scores: Cross-Hybridization: 39.0\%, Delta Tm: 26.0\%, Folding: 13.0\%, Position: 13.0\%, Lowcomplexity: $9.1 \%$. The probe length was adjusted between 44 and $52 \mathrm{bp}$ with an average of $48 \mathrm{bp}$ to ensure comparable hybridization strengths. Because OligoWiz was originally designed for use with single genomes in mind, it was necessary to modify the program, specifically the mechanisms screening for cross-hybridisation which needed to be less strict. A new scheme was devised by introducing a log-transformation in the underlying calculations. The net effect is negligible near the upper boundary of the score, but near the lower boundary it increases the discriminatory power of the method.

\section{Preparation of labeled double-stranded DNA}

Ten micrograms of total RNA from each sample was reverse transcribed using SuperScript II (Invitrogen, Carlsbad, CA) and Random Hexamer Primers (Invitrogen) according to the NimbleGen Arrays User's Guide
(Gene Expression Analysis v3.2). The generated cDNA was incubated with $1 \mu \mathrm{l}$ of $4 \mathrm{mg} / \mathrm{ml}$ RNase A solution (Promega Corporation, Madison, WI, USA) at $37^{\circ} \mathrm{C}$ for $10 \mathrm{~min}$, and then phenol-chloroform extracted. Samples were centrifuged in Phase Lock Gel Tubes (5 Prime, Hamburg, Germany) at $12,000 \times \mathrm{g}$ for 5 minutes and precipitated with $80 \%$ ethanol. Pellets were air dried in a SpeedVac and rehydrated in $20 \mu \mathrm{l}$ of ultrapure water (Ambion). Finally the samples were measured by NanoDrop to ensure that the cDNA met the following quality requirements: A260/A280 $\geq 1.8$ and A260/A230 $\geq 1.8$. NimbleGen One-Color DNA Labeling kit (NimbleGen Systems, Madison, WI) was used for Cy3 labeling of cDNA samples according to the NimbleGen Arrays User's Guide. Briefly, $1 \mu \mathrm{g}$ double-stranded cDNA was incubated for $10 \mathrm{~min}$ at $98^{\circ} \mathrm{C}$ with Cy3-random Nonamers and then quick-chilled in a ice-water bath for 10 min. The addition of $100 \mathrm{mM}$ of deoxynucleoside triphosphates and $100 \mathrm{U}$ of Klenow fragment (New England Biolabs, Ipswich, MA) was followed by incubation at $37^{\circ} \mathrm{C}$ for $2 \mathrm{~h}$. The reaction was stopped by adding 0.1 volumes of $0.5 \mathrm{M}$ EDTA, and the labeled cDNA was precipitated with isopropanol.

\section{Hybridization and analysis of arrays}

A hybridization kit (NimbleGen Systems, Madison, WI) was used for the hybridization step. Cy3-labeled samples were resuspended in the recommended amount of hybridization buffer and denatured at $95^{\circ} \mathrm{C}$ for $5 \mathrm{~min}$. Slides were placed in HX12 NimbleGen Mixer and $6 \mu \mathrm{l}$ of sample loaded though the fill port. Hybridization was performed for $20 \mathrm{~h}$ at $42^{\circ} \mathrm{C}$ (NimbleGen Hybridization System 16). The arrays were washed using a wash buffer kit (NimbleGen Systems), dried in a microarray dryer (NimbleGen), and scanned at a $5 \mu \mathrm{m}$ resolution using the NimbleGens MS 200 scanner (NimbleGen Systems).

\section{Quantitative real-time PCR}

Gene quantification was performed with a Rotor-Gene 6000 (Corbett Research, Sydney, Australia). The primers were designed using Primer3 (v. 0.4.0) [70]. The sequences of the primers are listed in Table 3. Each PCR was performed in a $25 \mu$ reaction mixture containing 12.5 $\mu \mathrm{l}$ QuantiTect SYBR Green PCR master mix (Qiagen, Hilden, Germany), a primer concentration of $0.3 \mu \mathrm{M}$ and $7 \mathrm{ng}$ of cDNA. Three biological replicas were included for each sample. The thermal cycling conditions were as follows: $15 \mathrm{~min}$ at $95^{\circ} \mathrm{C}$, followed by 40 cycles of $15 \mathrm{~s}$ at $94^{\circ} \mathrm{C}, 20 \mathrm{~s}$ at $55^{\circ} \mathrm{C}$, and $20 \mathrm{~s}$ at $72^{\circ} \mathrm{C}$. Data collection was performed during each extension phase. Positive controls (DNA), a negative control (distilled water), and RT-negative controls (total RNA 
Table 3 List of primers used for quantitative real-time PCR and sequencing

\begin{tabular}{|c|c|c|}
\hline $\begin{array}{l}\text { Target } \\
\text { gene }\end{array}$ & Forward primer & Reverse primer \\
\hline glyA & CAAGCGAATGCAGCTGTITA & CTGTGATGCCGTAGAGGACA \\
\hline pykA & GTACGGATGCGGTAATGCTT & GTACGGATGCGGTAATGCTT \\
\hline tpiA & CTACGAACCGATTTGGGCTA & CCGCCGTATTGGATAATCAC \\
\hline exbB1 & CCGGAATTGCGACAAATAGT & CCGTTCATTGGGTTATTTGG \\
\hline tonB1 & CATTGCATTGCCATAACCAG & AAAAGCGCCTGAAAAGATCA \\
\hline tbpA1 & AGGAATGACGTTGGTITGC & ATTGCAGGTAGGGCTGATTG \\
\hline copA & CTATGAAGCCAGCGTGATGA & CCAAATAGAACCGCTITCCA \\
\hline tonB2 & GCCTTGTACCGCATTAGGAA & CTCAGCCTAAGCCGAAAGAA \\
\hline hlyX & TTTACGTTGAGCGAACACG & ACGCCGTAATTTGTTCTTCG \\
\hline cirA & TACGCTCTCCGGTGTGTATG & GTTGCGGTAGAAGCACCTTT \\
\hline ywbN & TCGCAAATGGGCTTTAATTC & CTTTCAGCCAACCGTCTTGT \\
\hline $\begin{array}{l}\text { hpuB } \\
\text { (APL_1953) }\end{array}$ & AACATCGTGTAAGCGCCTCT & GCCCTCATCATCGGTATCAC \\
\hline $\begin{array}{l}\text { hpuB } \\
\text { (APL_1954) }\end{array}$ & ACGAAATGTTCTCCGGTACG & GATAGCCGGTCGAAACGTAA \\
\hline $\begin{array}{l}\text { hpuB } \\
\text { (APL_1955) }\end{array}$ & GGTTCGGCAACCTTATTTGA & CGTTCTAACCCGCGTAATTC \\
\hline IldD & AATGCCCTTGATTACCATCG & GTAAACCGCATACGCTTGGT \\
\hline hyaA & TTACCGGGTATGCCGATTA & GTGTCCTTCATCGCCGTATT \\
\hline hybB & TAATACCGGCAAAGGCTGTC & ACTTTCGCAAACTCGCCTAA \\
\hline napB & ACCCGTCGTGCTTGATACTT & GGCTTATACCAACCCGCATA \\
\hline nqrC & CCGTAGCTAAAGGTGCTTCG & TTAGCTCCCATTGCTGCTIT \\
\hline$f d x G$ & TACTGTTCTGTCGGCTGTGG & GACTTACCGGATGGTCAGGA \\
\hline ykgE & GTTAAACGACCGGCAATGT & AACAAACCTGTTGCGGTTC \\
\hline $\begin{array}{l}\text { hpuB } \\
\text { (APL_1954) } \\
\text { * }\end{array}$ & TCGGAGGAAAACTCGCTITA & TAACCACCGGTCGGAAAATA \\
\hline
\end{tabular}

All primers were designed by Primer3 http://frodo.wimit.edu/primer3/ and purchased at DNA Technology A/S, Risskov, Denmark. *Primers used for sequencing.

sample) were included in each run. Melting curve analysis was performed, which for all primer sets resulted in single product-specific melting curves.

\section{Relative quantification}

The Excel-based relative expression software tool, REST 2009 (V2.0.13), was applied for group wise comparison and statistical analysis of the qPCR data http://rest.genequantification.info/[71]. The relative expression ratios were calculated by a mathematical model, which included an efficiency correction for real-time PCR efficiency of the individual transcripts [72], as follows:

$$
\text { Ratio }=\left(E_{\text {target }}\right)^{\Delta \mathrm{CP}} \text { target }{ }^{(\text {control-sample })} /\left(E_{\text {ref }}\right)_{\text {ref }}^{\Delta \mathrm{CP}}(\text { control-sample })
$$

The relative expression ratio of a target gene was computed based on its real-time PCR efficiencies $(E)$ and the crossing point difference $(\triangle \mathrm{CP})$ for an unknown sample versus a control. For each gene, cDNA dilution curves were generated and used to calculate the
Table 4 Relative expression results from REST analysis of qPCR data

\begin{tabular}{|c|c|c|c|c|c|c|}
\hline No. & Gene & Type & $\begin{array}{l}\text { Reaction } \\
\text { Efficiency }\end{array}$ & Expression & Std. Error & $\begin{array}{c}P \\
(\mathrm{H} 1) \\
*\end{array}$ \\
\hline & glyA & Reference & 0.91 & 1.33 & & \\
\hline & pykA & Reference & 0.99 & 1.00 & & \\
\hline & tpiA & Reference & 0.99 & 0.75 & & \\
\hline 1 & exbB1 & Sample & 1.00 & 13.94 & $4.26-35.88$ & 0.000 \\
\hline 2 & APL_1953 & Sample & 0.99 & 6.82 & $2.45-20.84$ & 0.000 \\
\hline 3 & APL_1954 & Sample & 0.98 & 5.09 & $1.49-16.29$ & 0.000 \\
\hline 4 & APL_1955 & Sample & 1.00 & 6.68 & $2.44-20.64$ & 0.000 \\
\hline 5 & cirA & Sample & 0.85 & 2.26 & $0.92-5.30$ & 0.001 \\
\hline 6 & $y w b N$ & Sample & 1.00 & 3.76 & $1.87-7.70$ & 0.000 \\
\hline 7 & $\operatorname{cop} A$ & Sample & 1.00 & 6.98 & $2.79-17.86$ & 0.000 \\
\hline 8 & hlyx & Sample & 0.95 & 1.78 & $0.70-5.14$ & 0.017 \\
\hline 9 & tbpA1 & Sample & 0.90 & 7.82 & $2.62-18.50$ & 0.000 \\
\hline 10 & $\operatorname{ton} B 1$ & Sample & 0.94 & 12.60 & $3.56-34.29$ & 0.000 \\
\hline 11 & $\operatorname{ton} B 2$ & Sample & 1.00 & 1.65 & $0.75-3.66$ & 0.012 \\
\hline 12 & $\| d D$ & Sample & 0.98 & 15.32 & $1.69-90.73$ & 0.000 \\
\hline 13 & $n a p B$ & Sample & 0.94 & 0.18 & $0.07-0.58$ & 0.000 \\
\hline 14 & narc & Sample & 0.93 & 0.36 & $0.18-0.74$ & 0.000 \\
\hline 15 & $y k g E$ & Sample & 0.89 & 0.12 & $0.04-0.45$ & 0.000 \\
\hline 16 & hyaA & Sample & 1.00 & 0.05 & $0.02-0.21$ & 0.000 \\
\hline 17 & $f d x G$ & Sample & 1.00 & 0.30 & $0.07-1.37$ & 0.004 \\
\hline 18 & hybB & Sample & 0.93 & 0.09 & $0.03-0.37$ & 0.000 \\
\hline
\end{tabular}

*The hypothesis test represents the probability of the alternative hypothesis that the difference between the sample and control groups is due only to chance. Results are based on 6000 randomizations.

individual real-time PCR efficiencies $\left(E=10^{[-1 / \text { slope }]}\right)$. The geometric mean of the three internal reference genes was used to correct the raw values for the genes of interest (Table 4).

\section{Data analysis of Microarray data}

The data discussed in this publication have been deposited in NCBI's Gene Expression Omnibus [73] and are accessible through GEO Series accession number GSE24470 http://www.ncbi.nlm.nih.gov/geo/query/acc. cgi?acc=GSE24470. Data analysis of the microarrays was performed in "RGui" version 2.9.2 (2009-08-24) http:// cran.r-project.org/bin/windows/base/, using the package "Oligo". The Robust Multichip Average function was applied for normalization of the microarray data [74]. By this method, the expression measure is given in $\log _{2}$ base. Mean $\log _{2}$ expression values of the four biological replicates are given in Table 1 and 2. Two-way analysis of variance (ANOVA) was used to test the effect of treatment (F1: bacterial response to iron deficiency versus control) and serotype (F2 response between serotypes 1, 2, 3, 5, 6 and 7) and the combined effect of treatment and serotype (F1:F2). 


\section{Construction of genomic atlases}

The program BLASTatlas http://www.cbs.dtu.dk/ws/ BLASTatlas, was used for mapping and visualizing whole genome homology of expressed genes [75]. Using the published genome of A. pleuropneumoniae serotype 3 str. JL03 as a reference strain, the expression values of control cultures and iron depleted cultures of the six serotypes were compared to each other.

\section{Additional material}

Additional file 1: Figure S1. The effect of 2,2'-dipyridyl with and without the addition of exogenous iron. Results of QPCR expression analysis of A. pleuropneumoniae serotype 2 (A) and serotype 6 (B) grown in media with $300 \mu \mathrm{M}$ of 2,2'-dipyridyl only (dark blue bars) or with 300 $\mu \mathrm{M}$ of 2,2'-dipyridyl and $300 \mu \mathrm{M}$ of ammonium iron(II) sulphate hexahydrate (light blue bars).

\section{Abbreviations}

OM: outer membrane, Hb: haemoglobin, sRNA: small non-coding RNA, Fur: ferric-uptake regulator protein, COGs: Clusters of Orthologous Groups, qPCR: Real-time quantitative RT-PCR, FNR: Fumerate and Nitrate reduction Regulator, ArcA: Anoxic redox control protein A.

\section{Acknowledgements}

This work was supported by the Danish Research Council for Technology and Production Sciences (274-07-0127). The authors thank Anastasia Isbrand, Joanna Amenuvor and Lene Holberg Blicher for technical assistance. The authors thank Bujie Zhan, Jakob Hedegaard, Frank Panitz and Christian Bendixen for providing the draft sequences of $A$. pleuropneumoniae serotypes 2 and 6.

\section{Author details}

'National Veterinary Institute, Technical University of Denmark, Bülowsvej 27, DK-1790, Copenhagen, Denmark. ${ }^{2}$ National Food Institute, Technical University of Denmark, Kemitorvet, building 204, DK-2800 Kgs. Lyngby, Denmark.

\section{Authors' contributions}

All authors participated in conceiving and designing the study. KK performed growth studies, microarray and GPCR analysis and drafted the manuscript. CF designed the pan-genomic microarray and helped with the downstream data analysis and manuscript. MB, CF and ØA revised the manuscript. All authors read and approved the final manuscript.

Received: 20 October 2010 Accepted: 9 December 2010 Published: 9 December 2010

\section{References}

1. Pohl S, Bertschinger HU, Frederiksen W, Mannheim W: Transfer of Haemophilus pleuropneumoniae and the Pasteurella haemolytica-Like Organism Causing Porcine Necrotic Pleuropneumonia to the Genus Actinobacillus (Actinobacillus pleuropneumoniae comb. nov.) on the Basis of Phenotypic and Deoxyribonucleic Acid Relatedness. Int I Syst Bacteriol 1983, 33:510-514.

2. Bossé JT, Janson H, Sheehan BJ, Beddek AJ, Rycroft AN, Simon K, Langford PR: Actinobacillus pleuropneumoniae: pathobiology and pathogenesis of infection. Microbes Infect 2002, 4:225-235.

3. Perry MB, Altman E, Brisson JR, Beynon LM, Richards JC: Structural characteristics of the antigenic capsular polysaccharides and lipopolysaccharides involved in the serological classification of Actinobacillus (Haemophilus) pleuropneumoniae strains. Serodiag Immun Inf D 1990, 4:299-308.

4. Rosendal S, Boyd DA, Gilbride KA: Comparative virulence of porcine Haemophilus bacteria. Can J Comp Med 1985, 49:68-74.
5. Jacobsen MJ, Nielsen JP, Nielsen R: Comparison of virulence of different Actinobacillus pleuropneumoniae serotypes and biotypes using an aerosol infection model. Vet Microbiol 1996, 49:159-168.

6. Komal JPS, Mittal KR: Grouping of Actinobacillus Pleuropneumoniae Strains of Serotype-1 Through Serotype-12 on the Basis of Their Virulence in Mice. Vet Microbiol 1990, 25:229-240.

7. Rogers RJ, Eaves LE, Blackall PJ, Truman KF: The comparative pathogenicity of four serovars of Actinobacillus (Haemophilus) pleuropneumoniae. Aust Vet J 1990, 67:9-12.

8. Ramjeet M, Deslandes V, Gouré J, Jacques M: Actinobacillus pleuropneumoniae vaccines: from bacterins to new insights into vaccination strategies. Anim Health Res Rev 2008, 9:25-45.

9. Haesebrouck F, Chiers K, Van O, Ducatelle R: Actinobacillus pleuropneumoniae infections in pigs: the role of virulence factors in pathogenesis and protection. Vet Microbiol 1997, 58:239-249.

10. Fuller TE, Martin S, Teel JF, Alaniz GR, Kennedy MJ, Lowery DE: Identification of Actinobacillus pleuropneumoniae virulence genes using signature-tagged mutagenesis in a swine infection model. Microb Pathog 2000, 29:39-51.

11. Baltes N, Hennig-Pauka I, Gerlach GF: Both transferrin binding proteins are virulence factors in Actinobacillus pleuropneumoniae serotype 7 infection. FEMS Microbiol Lett 2002, 209:283-287.

12. Frey J: Virulence in Actinobacillus pleuropneumoniae and RTX toxins. Trends Microbiol 1995, 3:257-261.

13. Jacques M: Surface polysaccharides and iron-uptake systems of Actinobacillus pleuropneumoniae. Can J Vet Res 2004, 68:81-85.

14. Frey J: Detection, identification, and subtyping of Actinobacillus pleuropneumoniae. Methods Mol Biol 2003, 216:87-95.

15. Bertram TA: Quantitative morphology of peracute pulmonary lesions in swine induced by Haemophilus pleuropneumoniae. Vet Pathol 1985, 22:598-609.

16. Jensen $A E$, Bertram TA: Morphological and biochemical comparison of virulent and avirulent isolates of Haemophilus pleuropneumoniae serotype 5. Infect Immun 1986, 51:419-424.

17. Brandreth SR, Smith IM: Comparative virulence of some English strains of Haemophilus pleuropneumoniae serotypes 2 and 3 in the pig. Res Vet Sci 1987, 42:187-193.

18. Mittal KR, Higgins R, Larivière S, Leblanc D: A 2-mercaptoethanol tube agglutination test for diagnosis of Haemophilus pleuropneumoniae infection in pigs. Am J Vet Res 1984, 45:715-719.

19. Andrews SC, Robinson AK, Rodríguez-Quiñones F: Bacterial iron homeostasis. FEMS Microbiol Rev 2003, 27:215-237.

20. Massé $E$, Arguin M: Ironing out the problem: new mechanisms of iron homeostasis. Trends Biochem Sci 2005, 30:462-468.

21. Gerlach GF, Klashinsky S, Anderson C, Potter AA, Willson PJ: Characterization of two genes encoding distinct transferrin-binding proteins in different Actinobacillus pleuropneumoniae isolates. Infect Immun 1992, 60:3253-3261.

22. Gonzalez GC, Yu RH, Rosteck PR, Schryvers AB: Sequence, genetic analysis, and expression of Actinobacillus pleuropneumoniae transferrin receptor genes. Microbiology 1995, 141(Pt 10):2405-2416.

23. Tonpitak W, Thiede S, Oswald W, Baltes N, Gerlach GF: Actinobacillus pleuropneumoniae iron transport: a set of exbBD genes is transcriptionally linked to the $t b p B$ gene and required for utilization of transferrin-bound iron. Infect Immun 2000, 68:1164-1170.

24. Beddek AJ, Sheehan BJ, Bossé JT, Rycroft AN, Kroll JS, Langford PR: Two TonB Systems in Actinobacillus pleuropneumoniae: Their Roles in Iron Acquisition and Virulence. Infect Immun 2004, 72:701-708.

25. Srikumar R, Mikael LG, Pawelek PD, Khamessan A, Gibbs BF, Jacques M, Coulton JW: Molecular cloning of haemoglobin-binding protein $\mathrm{HgbA}$ in the outer membrane of Actinobacillus pleuropneumoniae. Microbiology 2004, 150:1723-1734

26. Deslandes V, Nash JH, Harel J, Coulton JW, Jacques M: Transcriptional profiling of Actinobacillus pleuropneumoniae under iron-restricted conditions. BMC Genomics 2007, 8:72.

27. Paustian ML, May BJ, Kapur V: Pasteurella multocida gene expression in response to iron limitation. Infect Immun 2001, 69:4109-4115.

28. Whitby PW, Vanwagoner TM, Seale TW, Morton DJ, Stull TL: Transcriptional profile of Haemophilus influenzae: effects of iron and heme. J Bacteriol 2006, 188:5640-5645. 
29. Roehrig SC, Tran HQ, Spehr V, Gunkel N, Selzer PM, Ullrich HJ: The response of Mannheimia haemolytica to iron limitation: implications for the acquisition of iron in the bovine lung. Vet Microbiol 2007, 121:316-329.

30. Chin N, Frey J, Chang CF, Chang YF: Identification of a locus involved in the utilization of iron by Actinobacillus pleuropneumoniae. FEMS Microbiol Lett 1996, 143:1-6.

31. Mikael LG, Pawelek PD, Labrie J, Sirois M, Coulton JW, Jacques M: Molecular cloning and characterization of the ferric hydroxamate uptake (fhu) operon in Actinobacillus pleuropneumoniae. Microbiol 2002, 148:2869-2882.

32. Mikael LG, Srikumar R, Coulton JW, Jacques M: fhuA of Actinobacillus pleuropneumoniae encodes a ferrichrome receptor but is not regulated by iron. Infect Immun 2003, 71:2911-2915.

33. Hsu YM, Chin N, Chang CF, Chang YF: Cloning and characterization of the Actinobacillus pleuropneumoniae fur gene and its role in regulation of Apxl and AfuABC expression. DNA Seq 2003, 14:169-181.

34. Jacobsen I, Gerstenberger J, Gruber AD, Bossé JT, Langford PR, HennigPauka I, Meens J, Gerlach GF: Deletion of the ferric uptake regulator Fur impairs the in vitro growth and virulence of Actinobacillus pleuropneumoniae. Infect Immun 2005, 73:3740-3744.

35. Chao $\mathrm{Y}$, Vogel J: The role of $\mathrm{Hfq}$ in bacterial pathogens. Curr Opin Microbiol 2010, 13:24-33.

36. Melnikow E, Dornan S, Sargent C, Duszenko M, Evans G, Gunkel N, Selzer PM, Ullrich HJ: Microarray analysis of Haemophilus parasuis gene expression under in vitro growth conditions mimicking the in vivo environment. Vet Microbiol 2005, 110:255-263.

37. Whitby PW, Seale TW, VanWagoner TM, Morton DJ, Stull TL: The iron/heme regulated genes of Haemophilus influenzae: comparative transcriptional profiling as a tool to define the species core modulon. BMC Genomics 2009, 10:6.

38. Nielsen KK, Boye M: Real-time quantitative reverse transcription-PCR analysis of expression stability of Actinobacillus pleuropneumoniae housekeeping genes during in vitro growth under iron-depleted conditions. Appl Environ Microbiol 2005, 71:2949-2954.

39. Tatusov RL, Koonin EV, Lipman DJ: A genomic perspective on protein families. Science 1997, 278:631-637.

40. Postle K: TonB and the gram-negative dilemma. Mol Microbio/ 1990, 4:2019-2025.

41. Challacombe JF, Inzana TJ: Comparative Genomics of Pasteurellaceae. In Pasteurellaceae: Biology, Genomics and Molecular Aspects. Edited by: Kuhnert P, Christensen H. Nordfolk, UK. Caister Academic Press; 2008:53-77.

42. Boyce JD, Wilkie I, Harper M, Paustian ML, Kapur V, Adler B: Genomic-scale analysis of Pasteurella multocida gene expression during growth within liver tissue of chickens with fowl cholera. Microbes Infect 2004, 6:290-298.

43. Whitby PW, Seale TW, Morton DJ, VanWagoner TM, Stull TL: Characterization of the Haemophilus influenzae tehB gene and its role in virulence. Microbiology 2010, 156:1188-1200.

44. Lewis LA, Gipson M, Hartman K, Ownbey T, Vaughn J, Dyer DW: Phase variation of $H p u A B$ and $H m b R$, two distinct haemoglobin receptors of Neisseria meningitidis DNM2. Mol Microbiol 1999, 32:977-989.

45. Touchon M, Hoede C, Tenaillon O, Barbe V, Baeriswyl S, Bidet P, Bingen $E_{\text {, }}$ Bonacorsi S, Bouchier C, Bouvet O, Calteau A, Chiapello H, Clermont O, Cruveiller S, Danchin A, Diard M, Dossat C, El Karoui M, Frapy E, Garry L, Ghigo JM, Gilles AM, Johnson J, Le Bouguénec C, Lescat M, Mangenot S, Martinez-Jéhanne V, Matic I, Nassif X, Oztas S, Petit MA, Pichon C, Rouy Z, Sain Ruf C, Schneider D, Tourret J, Vacherie B, Vallenet D, Médigue C, Rocha EPC, Denamur E: Organised genome dynamics in the Escherichia coli species results in highly diverse adaptive paths. PLoS Genet 2009, 5: e1000344.

46. Buettner FF, Bendalla IM, Bossé JT, Meens J, Nash JH, Härtig E, Langford PR, Gerlach GF: Analysis of the Actinobacillus pleuropneumoniae HlyX (FNR) regulon and identification of iron-regulated protein $B$ as an essential virulence factor. Proteomics 2009, 9:2383-2398.

47. Auger E, Deslandes V, Ramjeet M, Contreras I, Nash JHE, Harel J, Gottschalk M, Olivier M, Jacques M: Host-Pathogen Interactions of Actinobacillus pleuropneumoniae with Porcine Lung and Tracheal Epithelial Cells. Infect Immun 2009, 77:1426-1441.

48. Diarra MS, Dolence JA, Dolence EK, Darwish I, Miller MJ, Malouin F, Jacques M: Growth of Actinobacillus pleuropneumoniae is promoted by exogenous hydroxamate and catechol siderophores. Appl Environ Microbiol 1996, 62:853-859.
49. Curtis NA, Eisenstadt RL, East SJ, Cornford RJ, Walker LA, White AJ: Ironregulated outer membrane proteins of Escherichia coli K-12 and mechanism of action of catechol-substituted cephalosporins. Antimicrob Agents Chemother 1988, 32:1879-1886.

50. Nikaido H, Rosenberg EY: Cir and Fiu proteins in the outer membrane of Escherichia coli catalyze transport of monomeric catechols: study with beta-lactam antibiotics containing catechol and analogous groups. J Bacteriol 1990, 172:1361-1367.

51. McHugh JP, Rodriguez-Quiñones F, Abdul-Tehrani H, Svistunenko DA, Poole RK, Cooper CE, Andrews SC: Global iron-dependent gene regulation in Escherichia coli. A new mechanism for iron homeostasis. J Biol Chem 2003, 278:29478-29486.

52. Grass G: Iron transport in Escherichia coli: all has not been said and done. Biometals 2006, 19:159-172.

53. Cartron ML, Mitchell SA, Woodhall MR, Andrews SC, Watson KA: Preliminary $\mathrm{X}$-ray diffraction analysis of $Y c d B$ from Escherichia coli: a novel haemcontaining and Tat-secreted periplasmic protein with a potential role in iron transport. Acta Crystallogr Sect F Struct Biol Cryst Commun 2007, 63:37-41.

54. Ollinger J, Song KB, Antelmann H, Hecker M, Helmann JD: Role of the Fur regulon in iron transport in Bacillus subtilis. J Bacteriol 2006, 188:3664-3673.

55. Grosse C, Scherer J, Koch D, Otto M, Taudte N, Grass G: A new ferrous iron-uptake transporter, EfeU $(Y c d N)$, from Escherichia coli. Mol Microbiol 2006, 62:120-131.

56. Chillappagari S, Seubert A, Trip H, Kuipers OP, Marahiel MA, Miethke M: Copper Stress Affects Iron Homeostasis by Destabilizing Iron-Sulfur Cluster Formation in Bacillus subtilis. J Bacteriol 2010, 192:2512-2524.

57. Lin XM, Wu LN, Li H, Wang SY, Peng XX: Downregulation of TsX and OmpW and upregulation of $O m p X$ are required for iron homeostasis in Escherichia coli. J Proteome Res 2008, 7:1235-1243.

58. Allard M, Moisan $H$, Brouillette $E$, Gervais AL, Jacques M, Lacasse $P$, Diarra MS, Malouin F: Transcriptional modulation of some Staphylococcus aureus iron-regulated genes during growth in vitro and in a tissue cage model in vivo. Microbes Infect 2006, 8:1679-1690.

59. Angelini S, Gerez C, Ollagnier- de Choudens S, Sanakis Y, Fontecave M, Barras F, Py B: NfuA, a new factor required for maturing $\mathrm{Fe} / \mathrm{S}$ proteins in Escherichia coli under oxidative stress and iron starvation conditions. J Biol Chem 2008, 283:14084-14091.

60. Baltes N, N'diaye M, Jacobsen ID, Maas A, Buettner FF, Gerlach GF: Deletion of the anaerobic regulator $H / y X$ causes reduced colonization and persistence of Actinobacillus pleuropneumoniae in the porcine respiratory tract. Infect Immun 2005, 73:4614-4619.

61. Buettner FF, Bendallah IM, Bosse JT, Dreckmann K, Nash JH, Langford PR, Gerlach GF: Analysis of the Actinobacillus pleuropneumoniae ArcA regulon identifies fumarate reductase as a determinant of virulence. Infect Immun 2008, 76:2284-2295.

62. Massé E, Majdalani N, Gottesman S: Regulatory roles for small RNAs in bacteria. Curr Opin Microbiol 2003, 6:120-124.

63. Massé E, Gottesman S: A small RNA regulates the expression of genes involved in iron metabolism in Escherichia coli. Proc Natl Acad Sci USA 2002, 99:4620-4625.

64. Foote SJ, Bossé JT, Bouevitch AB, Langford PR, Young NM, Nash JHE: The Complete Genome Sequence of Actinobacillus pleuropneumoniae L20 (Serotype 5b). J Bacteriol 2008, 190:1495-1496.

65. Xu Z, Zhou Y, Li L, Zhou R, Xiao S, Wan Y, Zhang S, Wang K, Li W, Li L, Jin H, Kang M, Dalai B, Li T, Liu L, Cheng Y, Zhang L, Xu T, Zheng H, Pu S, Wang B, Gu W, Zhang XL, Zhu GF, Wang S, Zhao GP, Chen H: Genome Biology of Actinobacillus pleuropneumoniae JL03, an Isolate of Serotype 3 Prevalent in China. PLOS ONE 2008, 3:e1450

66. Zhan B, Angen O, Hedegaard J, Bendixen C, Panitz F: The Draft Genome Sequences of Actinobacillus pleuropneumoniae Serotypes 2 and 6 . J Bacteriol 2010, 192:5846-5847.

67. Hobohm U, Scharf M, Schneider R, Sander C: Selection of representative protein data sets. Protein Sci 1992, 1:409-417.

68. Wernersson R, Nielsen HB: OligoWiz 2.0integrating sequence feature annotation into the design of microarray probes. Nucleic Acids Res 2005, 33:W611-W615.

69. Wernersson R, Juncker AS, Nielsen HB: Probe selection for DNA microarrays using OligoWiz. Nat Protoc 2007, 2:2677-2691. 
70. Rozen S, Skaletsky H: Primer3 on the WWW for general users and for biologist programmers. Methods Mol Biol 2000, 132:365-386.

71. Pfaffl MW, Horgan GW, Dempfle L: Relative expression software tool (REST) for group-wise comparison and statistical analysis of relative expression results in real-time PCR. Nucl Acids Res 2002, 30:e36.

72. Pfaffl MW: A new mathematical model for relative quantification in realtime RT-PCR. Nucl Acids Res 2001, 29:e45,

73. Edgar R, Domrachev M, Lash AE: Gene Expression Omnibus: NCBI gene expression and hybridization array data repository. Nucl Acids Res 2002, 30:207-210.

74. Irizarry RA, Hobbs B, Collin F, Beazer-Barclay YD, Antonellis KJ, Scherf U, Speed TP: Exploration, normalization, and summaries of high density oligonucleotide array probe level data. Biostatistics 2003, 4:249-264.

75. Hallin PF, Binnewies TT, Ussery DW: The genome BLASTatlas-a GeneWiz extension for visualization of whole-genome homology. Mol Biosyst 2008, 4:363-371.

doi:10.1186/1471-2164-11-698

Cite this article as: Klitgaard et al:: Comparative profiling of the

transcriptional response to iron restriction in six serotypes of

Actinobacillus pleuropneumoniae with different virulence potential. BMC

Genomics 2010 11:698.

\section{Submit your next manuscript to BioMed Central} and take full advantage of:

- Convenient online submission

- Thorough peer review

- No space constraints or color figure charges

- Immediate publication on acceptance

- Inclusion in PubMed, CAS, Scopus and Google Scholar

- Research which is freely available for redistribution

Submit your manuscript at www.biomedcentral.com/submit
C Biomed Central 